\title{
VALIDASI PREDIKSI DURASI DENGAN METODE EARNED SCHEDULE UNTUK GEDUNG BERTINGKAT DI JAKARTA
}

\author{
Melati Nurevita ${ }^{1}$ dan Basuki Anondho ${ }^{2}$ \\ ${ }^{1}$ Program Studi Sarjana Teknik Sipil, Universitas Tarumanagara, Jl. Letjen S. Parman No.1 Jakarta \\ Melati.325150185@stu.untar.ac.id \\ ${ }^{2}$ Program Studi Sarjana Teknik Sipil, Universitas Tarumanagara, Jl. Letjen S. Parman No.1 Jakarta \\ basukia@ft.untar.ac.id
}

Masuk: 17-01-2020, revisi: 16-02-2020, diterima untuk diterbitkan: 26-02-2020

\begin{abstract}
The problem of project delays is often found as the construction industry develops. Various methods have been developed to overcome this problem, one of them is Earned Schedule. This method was developed from Earned Value by replacing the cost indicators contained in Earned Value into a time indicator. This study aims to determine whether the Earned Schedule method is feasible to predict the final duration for a multi-storey building project in Jakarta.This research was conducted by comparing the average of two populations between the average population duration with Earned Schedule and the average population duration of realization taken from reality. Furthermore, the sample of the population average is tested through the hypothesis test of the average difference to find out whether the two samples are in the same population. The data collected in this study were 52 on-going $s$-curve data and 35 predicted s-curve data. As a result, the final duration prediction population using the Earned Schedule method does not have an average difference with the predicted final duration population. Thus, the Earned Schedule method is considered appropriate to be used to predict the final duration of a high rise building project in Jakarta.
\end{abstract}

Keywords: prediction duration; Earned Value; Earned Schedule; validation

\begin{abstract}
ABSTRAK
Masalah keterlambatan proyek sering ditemukan seiring berkembangnya industri konstruksi. Berbagai metode dikembangkan untuk mengatasi masalah ini, salah satu metode tersebut adalah Earned Schedule. Metode ini dikembangkan dari Earned Value dengan mengganti indikator biaya yang terdapat pada Earned Value menjadi indikator waktu. Penelitian ini bertujuan untuk mengetahui apakah metode Earned Schedule layak digunakan untuk memprediksi durasi akhir untuk proyek gedung bertingkat di Jakarta. Penelitian ini dilakukan dengan cara dengan membandingkan rata-rata dua populasi antara rata-rata populasi durasi dengan Earned Schedule dan rata-rata populasi durasi realisasi yang diambil dari kenyataan. Selanjutnya sampel rata-rata populasi tersebut diuji melalui uji hipotesis selisih rata-rata untuk mengetahui apakah kedua sampel tersebut berada dalam satu populasi yang sama. Data yang terkumpul pada penelitian ini adalah sebanyak 52 data kurva-s on going dan 35 data kurva-s realisasi. Hasilnya, populasi prediksi durasi akhir dengan metode Earned Schedule tidak memiliki selisih rata-rata dengan populasi prediksi durasi akhir realisasi. Dengan demikian, metode Earned Schedule dinilai cukup layak digunakan untuk memprediksi durasi akhir proyek gedung bertingkat di Jakarta.
\end{abstract}

Kata Kunci: prediksi durasi; Earned Value; Earned Schedule; validasi

\section{PENDAHULUAN}

Perkiraan jadwal proyek merupakan elemen penting dari manajemen proyek untuk memastikan proyek berjalan tepat waktu. Seorang manajer proyek mengikuti status dan tren terkini dari kinerja proyek dan memprediksi kemungkinan hasil proyek sehingga hasilnya bisa tepat waktu (Kim dan Kim, 2014).

Di lain sisi prediksi durasi akhir proyek umum dilakukan dengan pendekatan Earned Value (EV) yang dikembangkan sekitar tahun 1967 oleh lembaga pemerintah federal Amerika Serikat. Earned Value (EV) merupakan sebuah metode untuk mengontrol proyek yang mampu memudahkan manajer proyek dalam memperkirakan kondisi akhir suatu proyek dalam hal biaya dan waktu (Anondho, 2018). EV diharapkan sebagai 
alat perkiraan durasi yang terpercaya (Lipke et al., 2007). EV telah diterima secara luas, yang telah berubah sebagai singkatan Earned Value Management, sebagai monitoring kinerja, analisis dan sistem peramalan (Kim \& Kim, 2014).

Earned Value Management (EVM) memiliki pandangan tentang ruang lingkup, waktu, biaya proyek, terlepas dari jenis, ukuran, maupun tingkat kerumitan proyek. Earned Value Management (EVM) secara umum digunakan untuk menganalisa performa proyek serta sebagai alat peringatan bila terjadi resiko pertambahan biaya dan pemunduran jadwal (Anondho et al., 2017). Dalam perkembangannya, penggunaan EV tradisional untuk memprediksi durasi mendapat kritik karena perhitungannya berdasarkan biaya (Lipke, 2009). EVM telah dikembangkan untuk menyediakan jadwal yang andal dan bermanfaat untuk informasi kinerja. Perkembangannya adalah Earned Schedule (ES) (Lipke, 2003). Secara singkat, metode ini menghasilkan indikator berbasis waktu, tidak seperti indikator berbasis biaya kontra-intuitif untuk jadwal kinerja yang ditawarkan oleh EVM (Lipke, 2011). Dikembangkan oleh (Lipke, 2003), ES dianggap sebagai salah satu metode utama untuk analisis jadwal dan perkiraan waktu (Anondho, 2018).

Penelitian Byung-cheol dan Hyung-Jin, 2014, menunjukan bahwa metode Earned Value Management (EVM) yang menggunakan SPI(c) memberikan hasil yang hampir sama dengan SPI(t) namun pada SPI(c) menunjukan perkiraan yang biasanya tidak seakurat $\mathrm{SPI}(\mathrm{t})$ terutama pada jadwal proyek dengan kurva $\mathrm{s}$ tidak linear. Berdasarkan penelitian tersebut metode Earned Value Management (EVM) yang menggunakan SPI(\$) dinilai kurang akurat dalam memprediksi durasi akhir proyek.

Sementara itu (Lipke, 2009) melakukan penelitian untuk membandingkan metode Earned Value (EV) dengan metode Earned Schedule (ES). Strategi analisis penelitian ini adalah dengan data proyek dipisah menjadi tujuh rentang persen lengkap untuk mengisolasi karakteristik perkiraan mungkin atau kecenderungan antara metode. Standar deviasi dari perkiraan pada durasi akhir yang sebenarnya dihitung untuk setiap proyek dan setiap persen jarak pengujian. Hasil penelitian ini yaitu hipotesa nol, Earned Value (EV) memberikan perkiraan yang lebih baik, ditolak untuk setiap persen yang diperiksa.

Berdasarkan permasalahan yang ditemukan diatas penelitian ini akan membahas apakah metode Earned Schedule (ES) dapat digunakan untuk memprediksi durasi akhir proyek gedung bertingkat di Jakarta dan sekitarnya. Tujuan dari penelitian ini adalah untuk mengetahui apakah metode Earned Schedule (ES) dapat digunakan untuk memprediksi durasi proyek gedung bertingkat di Jakarta dan sekitarnya.

\section{Prediksi Durasi dengan Earned Schedule}

Menurut (David dan Higgins, 2012) Earned Schedule (ES) adalah perpanjangan dari Earned Value Management (EVM) yang menyediakan kemampuan analisis jadwal. Earned Schedule (ES) diperkenalkan pada tahun 2003 oleh artikel "Schedule Is Different" (Lipke, 2003), dianggap sebagai salah satu metode utama untuk analisis jadwal dan perkiraan waktu (PMI 2011). Keuntungan yang signifikan dari penerapan Earned Schedule (ES) adalah bahwa metode ini menyediakan kemampuan untuk memperkirakan durasi proyek dan tanggal penyelesaian yang diharapkan (Lipke, 2011).

Kelebihan ES dibandingkan dengan EV adalah memungkinkan pengukuran indikator jadwal dalam waktu bukannya unit mata uang dan menghilangkan kekurangan SPI yang cenderung 1,0 saat proyek mendekati penyelesaian meskipun itu terlambat atau lebih cepat dari jadwal. Karenanya, konsep ES memperkenalkan SPI baru berbasis waktu, juga dinotasikan sebagai SPI(t) (Narbaev and De Marco, 2014). Parameter Earned Schedule (ES) sama seperti Earned Value Management (EVM) yaitu membutuhkan BCWS dan BCWP tetapi tanpa menggunakan ACWP, karena BCWP akan diproyeksikan ke BCWS kemudian mengukur unit waktu untuk mendapatkan nilai ES.

\section{Validasi dengan Uji Hipotesis Selisih Rata-rata}

Hipotesis pada dasarnya merupakan suatu anggapan yang mungkin benar dan sering digunakan untuk dasar pengambilan keputusan atau untuk dasar penelitian lebih lanjut. Dugaan pada hipotesis bisa salah. Oleh karna itu, apabila akan digunakan sebagai dasar pengambilan keputusan, hipotesis harus diuji terlebih dahulu menggunakan data hasil observasi yang benar-benar dikumpulkan berdasarkan kenyataan (Wicaksono, 2006). Pengujian terhadap suatu hipotesis atau kesimpulan akan menghasilkan kesimpulan menerima atau menolak hipotesis tersebut. Pada uji hipotesis terdapat nilai statistik $\mathrm{Z}$ yaitu nilai yang ditentukan dari informasi sampel yang digunakan untuk menentukan apakah penelitian tersebut menolak atau menerima hipotesis nol (Ho). 


\section{METODE PENELITIAN}

\section{Pengumpulan Data Kurva-S Proyek}

Pengumpulan data dengan metode dokumentasi atau arsip dilakukan dengan mengumpulkan data Kurva-S. Ada terdapat dua data Kurva-S yang akan dikumpulkan dalam penelitian ini yaitu, data Kurva-S on-going atau Kurva-S dari proyek yang sedang berjalan dan data Kurva-S realisasi atau Kurva-S dari proyek yang sudah selesai. Data Kurva-S proyek berjalan dikumpulkan dengan mengajukan permohonan kepada proyek. Sedangkan, data Kurva-S proyek yang sudah selesai atau data durasi proyek yang sudah selesai dikumpulkan dengan mengajukan permohonan kepada perusahaan jasa konstruksi. Data Kurva-S yang dipakai minimal memiliki nilai bobot rencana, bobot realisasi dan memiliki durasi total rencana dari proyek konstruksi tersebut. Data dari Kurva-S tersebut akan dipakai untuk menghitung nilai Earned Schedule.

\section{Perhitungan Durasi dengan Metode Earned Schedule (ES)}

Setelah mendapat data kurva-s on going, selanjutnya dihitung nilai ES. Dalam penelitian ini, dilakukan dengan menggunakan program Microsoft Excel agar lebih mudah dilakukan. Nilai ES ditemukan dengan menggunakan EV untuk mengidentifikasi di mana peningkatan waktu PV nilai biaya seharusnya terjadi (Lipke, 2012). Konsep metode Earned Schedule dapat dilihat pada Gambar 1.

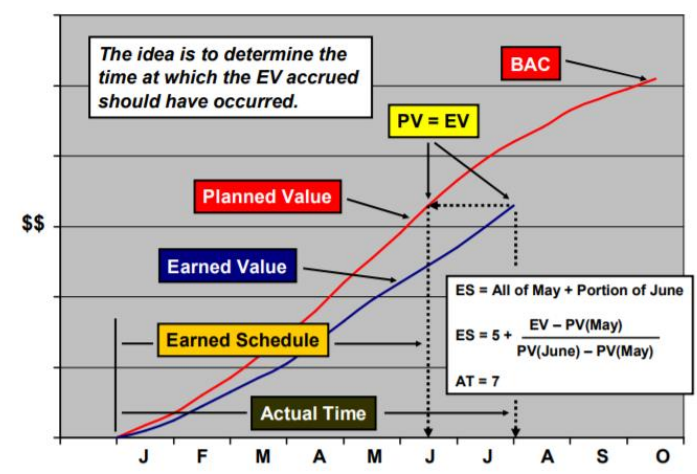

Gambar 1. Konsep Dasar Earned Schedule (ES) (Lipke, 2012)

Dari gambar tersebut, didapat nilai C dan I:

- $\quad \mathrm{C}=$ Nilai periode yang ditentukan dengan menghitung jumlah penambahan waktu dari pengukuran kinerja dasar atau Performance Measurement Baseline (PMB) yang memenuhi kondisi, BCWP > BCWS.

- $\quad \mathrm{I}=$ Nilai hasil interpolasi linear untuk menentukan nilai PMB pada titik yang ditinjau dengan persamaan:

$$
\mathrm{I}=\left(\mathrm{BCWP}_{-\mathrm{BCWS}}\right) /\left(\mathrm{BCWS}_{\mathrm{C}+1}-\mathrm{BCWS}_{\mathrm{C}}\right)
$$

Dengan demikian nilai ES (Earned Schedule) dapat dihitung dengan rumus berikut (Lipke, 2012):

$$
\mathrm{ES}=\mathrm{C}+\mathrm{I}
$$

Setelah menerapkan rumus tersebut maka akan didapat nilai ES perminggu didalam satu proyek. Cara ini diulang untuk mencari nilai ES pada waktu penyelesaian setiap data proyek yang didapat.

\section{Perhitungan EAC dengan metode Earned Schedule (ES)}

Selanjutnya karena data yang digunakan pada Earned Schedule (ES) berbasis waktu dan bukan biaya, maka perhitungan Schedule Variance $(\mathrm{t})$ dan Schedule Perfomance Index ( $\mathrm{t}$ ) dapat dihitung dengan rumus:

- $\quad$ Schedule Variance (time) atau SV(t)

$$
\mathrm{SV}(\mathrm{t})=\mathrm{ES}-\mathrm{AT}
$$


- Schedule Performance Index (time) atau SPI(t)

$$
\mathrm{SPI}(\mathrm{t})=\frac{\mathrm{ES}}{\mathrm{AT}}
$$

Keterangan:

$\mathrm{AT}=$ Actual Time, yaitu waktu aktual dari durasi proyek yang diamati

$\mathrm{ES}=$ Nilai dari Earned Schedule yang diperoleh

Nilai dari indikator tersebut menghasilkan data yang dapat dipergunakan untuk dapat memperkirakan durasi akhir proyek pada fase awal ataupun akhir suatu proyek. Nilai perkiraaan durasi proyek dari metode ES yaitu Estimate at Completion (EAC) dapat dihitung menggunakan rumus (Lipke, 2009):

$$
\mathrm{EAC}(\mathrm{t})=\mathrm{AT}+\frac{\mathrm{PD}-\mathrm{ES}}{\mathrm{SPI}(\mathrm{t})}
$$

Keterangan:

$\mathrm{PD}=$ Project Duration, yaitu durasi total proyek

Dengan rumus diatas maka didapatkan nilai EAC per minggu selama sejauh mana proyek tersebut berjalan. Nilai EAC tersebut kemudian dibagi berdasarkan luas lantai masing-masing proyek untuk menyamakan semua data dalam satuan besaran meter persegi. Rumus EAC/m2 dapat dilihat dibawah:

$$
E A C\left(\frac{\text { durasi }}{m^{2}}\right)=\frac{E A C(t)}{\text { Luas Lantai }}
$$

Setelah itu, EAC per minggu tersebut di rata-rata untuk mendapatkan EAC/m2 per satu proyek.

\section{Perhitungan Prediksi Akhir Rata - Rata}

Setelah diperhitungan sebelumnya didapat nilai EAC/m2 pertiap satu proyek, selanjutnya nilai EAC/m2 dari total seluruh proyek dirata - rata. Cara yang sama juga diterapkan untuk data proyek yang sudah terealisasi, durasi dari masing-masing proyek dibagi luas lantainya untuk menyamakan semua data dalam satuan besaran meter persegi dan akan menghasilkan nilai durasi realisasi (minggu)/m2 yang nantinya seluruh durasi realisasi $/ \mathrm{m} 2$ tersebut di rata - rata dan dicari standar deviasinya dengan menggunakan Excel untuk selanjutnya dilakukan uji hipotesis selisih rata-rata.

\section{Uji Hipotesis dengan Selisih Rata - Rata}

Untuk mengetahui apakah hasil perhitungan sampel durasi akhir proyek dengan metode Earned Schedule (ES) merupakan bagian dari durasi realisasi nyata pelaksanaan proyek, maka dilakukan perbandingan antara rata-rata perhitungan prediksi durasi ES dengan rata-rata realisasi pelaksanaan proyek konstruksi berdasarkan data nyata. Perbandingan dilakukan dengan melakukan uji hipotesis bahwa sampel rata-rata hasil perhitungan durasi akhir dengan metode ES merupakan satu populasi dengan rata-rata data sampel nyata realisasi proyek.

Langkah-langkah pengujian hipotesis ini sama seperti satu rata-rata, tetapi untuk uji statistik menggunakan rumus:

- Jika standar deviasi populasi diketahui

$$
Z=\frac{\left(\overline{x_{1}}-\overline{x_{2}}\right)-\left(\mu_{1}-\mu_{2}\right)}{\sigma_{x 1-x 2}} \text { dengan } \sigma_{x 1-x 2}=\sqrt{\frac{\sigma 1^{2}}{n 1}+\frac{\sigma 2^{2}}{n 2}}
$$

Berikut adalah langkah-langkah pengujian hipotesis selisih rata-rata untuk populasi independen (Anondho, 2018):

- Langkah $1:$ Menentukan formulasi hipotesis

Para ahli menyebutkan ada dua hipotesis dalam satu pengujian, yaitu:

a. Hipotesis nol $\left(\mathrm{H}_{\mathrm{o}}\right)$ adalah suatu pernyataan mengenai suatu populasi yang akan diuji.

Biasanya hipotesis nol dinyatakan dengan sama dengan $(=)$.

Contoh : $\mathrm{H}_{\mathrm{o}}: \mu_{1}=\mu_{2}$

b. Hipotesis alternatif $\left(\mathrm{H}_{1}\right)$ adalah suatu pernyataan yang diterima jika data sampel memberikan cukup bukti bahwa hipotesis nol ditolak.

Biasanya hipotesis alternatif dinyatakan dengan lebih besar (>), lebih kecil $(<)$, atau tidak sama dengan $(\neq)$.

Contoh : $\mathrm{H}_{1}: \mu_{1} \neq \mu_{2} \rightarrow$ uji dua-ujung

$\mu_{1}>\mu_{2} \rightarrow$ uji satu-ujung

$\mu_{1}<\mu_{2} \rightarrow$ uji satu-ujung 
- Langkah 2 : Menentukan taraf nyata atau tingkat resiko $(\alpha)$ sebagai dasar untuk menerima atau menolak hipotesis nol.

$$
\text { Taraf nyata }(\alpha)=1 \text { - tingkat keyakinan }
$$

Semakin besar tingkat keyakinan (confident interval) yang digunakan maka semakin rendah penolakan terhadap hipotesis nol (Ho). Pada umumnya tingkat keyakinan yang dipakai untuk bidang teknik adalah 95\% atau 99\%, namun dapat dimungkinkan menggunakan besaran tingkat keyakinan lain sesuai dengan tujuan penelitian.

- $\quad$ Langkah 3 : Perhitungan uji Z.

Statistik pengujian adalah sebuah nilai yang ditentukan dari informasi sampel yang digunakan untuk menentukan apakah penelitian ini menolak atau menerima hipotesis nol (Ho). Alat uji statistik menggunakan distribusi-distribusi probabilitas teoritis yang antara lain meliputi uji $\mathrm{Z}, \mathrm{t}, \mathrm{F}, \chi^{2}$ dan lainlain. Distribusi dari pengujian statistik digunakan untuk menghitung sejumlah probabilitas dengan nilai yang mungkin.

- Langkah 4 : Menentukan daerah keputusan.

Menentukan daerah keputusan berdasarkan nilai kritis yang diperoleh dari taraf nyata. Dari sejumlah nilai yang mungkin, dipilih satu daerah yang dianggap dapat mewakili bukti yang paling ekstrim untuk menolak hipotesis nol. Ini dinamakan daerah keputusan dari pengujian statistik atau daerah kritis (daerah penolakan). Daerah keputusan dari pengujian statistik yang digunakan yaitu: Daerah keputusan untuk dua arah (two tail) yang terdapat daerah penolakan $\mathrm{H}_{\mathrm{o}}$ dua sisi yaitu terletak di ekor sebelah kiri dan ekor sebelah kanan. Karena daerah penolakan ada dua, maka taraf nyata adalah $\alpha / 2$. Pengujian dua arah dipergunakan jika $\mathrm{H}_{1}$ menggunakan tanda $\neq$ (tidak sama dengan). Berikut gambar 2 adalah penggambaran daerah keputusan untuk dua arah

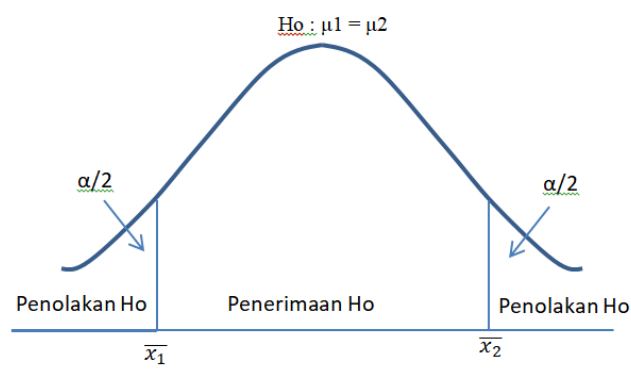

Gambar 2. Daerah Keputusan untuk Dua Arah

- Langkah 5: Pengambilan keputusan

Mengambil kesimpulan dengan melihat letak nilai uji statistik dengan daerah keputusan (daerah penolakan).

a. Jika hasil uji statistik berada dalam daerah penolakan, maka kesimpulannya adalah hipotesis itu salah, sehingga tolak hipotesis nol.

Untuk uji satu arah:

Jika $\mathrm{Z}<-\mathrm{Z}_{\alpha}$ maka Ho ditolak

atau

Jika $\mathrm{Z}>\mathrm{Z}_{\alpha}$ maka Ho ditolak

Untuk uji dua arah:

Jika $Z<-Z_{\alpha / 2}$ atau $Z>Z_{\alpha / 2}$ maka Ho ditolak

b. Sedangkan, jika pengujian statistik berada di luar daerah penolakan, maka kesimpulan yang diambil adalah tidak terdapat bukti yang cukup untuk menolak hipotesis, sehingga hipotesis nol diterima.

Untuk uji satu arah:

Jika $Z \geq-Z_{\alpha}$ maka Ho diterima

atau

Jika $\mathrm{Z} \leq \mathrm{Z}_{\alpha}$ maka Ho diterima 
Untuk uji dua arah:

Jika $-\mathrm{Z}_{\alpha / 2} \leq \mathrm{Z} \leq \mathrm{Z}_{\alpha / 2}$ maka Ho diterima

Metode penelitian menjelaskan secara rinci tahapan penelitian dari mulai persiapan sampai penarikan kesimpulan. Prosedur analisis, sumber data, teknik pengumpulan data, dan teknik analisis juga perlu dipaparkan secara jelas dan berurutan sesuai urutan pelaksanaan penelitian. Penulis diperkenankan mencantumkan diagram alir penelitian.

\section{HASIL DAN PEMBAHASAN}

Data Kurva-S on-going yang terkumpul untuk penelitian ini berjumlah 52 proyek yang didapatkan dengan cara mengajukan permohonan kepada proyek dan data Kurva-S realisasi yang terkumpul sebanyak 35 data proyek yang didapatkan dengan cara mengajukan permohonan kepada perusahaan jasa konstruksi.

Data dari 52 proyek on-going di Jakarta menghasilkan nilai rata-rata EAC/m2 dengan menggunakan metode Earned Schedule adalah 0,0028 dengan standar deviasi 0,003829. Data dari 35 proyek realisasi menghasilkan durasi rata-rata realisasi dalam minggu/m2 adalah 0,002792 dengan standar deviasi 0,001941.

Setelah mendapatkan hasil rata-rata dari kedua populasi, maka selanjutnya adalah melakukan uji hipotesis selisih rata-rata untuk mengetahui apakah ada perbedaan yang signifikan diantara kedua populasi tersebut. Hipotesis dapat dirumuskan sebagai berikut:

$$
\begin{aligned}
& \text { Ho }: \mu 1=\mu 2 \\
& \text { H1 }: \mu 1 \neq \mu 2
\end{aligned}
$$

Keterangan :

$\mu 1=$ Populasi prediksi durasi dengan metode ES (Earned Schedule)

$\mu 2=$ Populasi durasi realisasi proyek yang telah selesai

Dalam penelitian ini digunakan angka tingkat kepercayaan sebesar 95\% sehingga diperoleh nilai $Z_{\alpha / 2}= \pm 1.96$.

Nilai rata-rata dan standar deviasi dari kedua populasi dapat dilihat pada tabel 1 berikut ini.

Tabel 1. Nilai Rata - Rata dan Standar Deviasi

\begin{tabular}{cc}
\hline Keterangan & Nilai \\
\hline $\mathrm{X} 1$ & 0.002800 \\
\hline $\mathrm{X} 2$ & 0.002792 \\
\hline$\sigma 1$ & 0.003829 \\
\hline$\sigma 2$ & 0.001941 \\
\hline $\mathrm{n} 1$ & 52 \\
\hline $\mathrm{n} 2$ & 35
\end{tabular}

Keterangan:

$\mathrm{X} 1=\mathrm{Rata}-$ rata $\mathrm{EAC} / \mathrm{m} 2$

$\mathrm{X} 2=$ Rata - Rata durasi akhir realisasi proyek $/ \mathrm{m} 2$

$\sigma 1=$ Standar Deviasi dari perhitungan EAC/m2

$\sigma 2=$ Standar Deviasi dari durasi akhir realisasi proyek

n1 = Jumlah sampel Kurva-S on-going

n2 = Jumlah Sampel Kurva-S realisasi

Perhitungan dilakukan dengan rumus (7) sebagai berikut:

$$
\begin{aligned}
\sigma_{\mathrm{x} 1-\mathrm{x} 2} & =\sigma_{\mathrm{x} 1-\mathrm{x} 2}=\sqrt{\frac{\sigma 1^{2}}{\mathrm{n} 1}+\frac{\sigma 2^{2}}{\mathrm{n} 2}} \\
& =\sqrt{\frac{0.003829^{2}}{52}+\frac{0.001941^{2}}{35}} \\
& =0.0005310
\end{aligned}
$$




$$
\begin{aligned}
\mathrm{Z} & =\frac{(\mathrm{X} 1-\mathrm{X} 2)-(\mu 1-\mu 2)}{\sigma x 1-x 2} \\
& =\frac{(0.002800-0.002792)-(0)}{0.0005310} \\
& =0.01506
\end{aligned}
$$

Angka $\mathrm{Z}$ yang didapatkan sebesar 0.01506 yang masih berada didalam rentang $\mathrm{Z}_{\alpha / 2}= \pm 1.96$. Berdasarkan hasil tersebut maka uji hipotesis atas Ho yang menyatakan bahwa populasi prediksi durasi dengan metode Earned Schedule sama dengan populasi durasi akhir realisasi dapat diterima.

\section{KESIMPULAN DAN SARAN}

\section{Kesimpulan}

Kesimpulan dari penelitian ini adalah hasil uji hipotesis selisih dua rata-rata terhadap dua populasi sampel, yaitu sampel data Earned Schedule dan sampel data proyek yang sudah selesai, tidak terdapat perbedaan sehingga dapat ditarik kesimpulan bahwa metode Earned Schedule cukup layak dipergunakan sebagai prediksi durasi akhir proyek gedung bertingkat di Jakarta.

\section{Saran}

Saran yang dapat diberikan pada penelitian ini adalah:

1. Penelitian ini dilakukan hanya berdasarkan data dari gedung bertingkat tinggi, agar validasi bisa lebih menyeluruh terhadap semua jenis bangunan gedung bertingkat, maka, penelitian selanjutnya dapat memperhitungkan data dari gedung bertingkat rendah dan gedung bertingkat sedang

2. Batasan dalam penelitian ini hanya data proyek yang terdapat didaerah Jakarta dan sekitarnya, agar kontraktor yang ada di Indonesia bisa lebih yakin dalam memprediksi durasi akhir dengan metode Earned Schedule, maka, penelitian lebih lanjut dapat memperluas penelitian ini dengan menggunakan data dari proyek di Indonesia.

\section{DAFTAR PUSTAKA}

Anondho, B., Wiyanto, H., dan Putra, D.W. "Model Validasi Penerapan Hasil Pengembangan Earned Value Method Untuk Perkiraan Durasi Akhir Proyek Konstruksi Di Jakarta”. Konferensi Nasional Teknik Sipil, Vol. 11. 2017.

Anondho, B. "Pengembangan Model Prediksi Durasi Probabilistik Proyek Pembangunan Gedung Bertingkat Tinggi Berbasis Faktor Pengaruh Eksternal Terukur," Disertasi, Universitas Indonesia, Indonesia. 2018.

Kim, Byung-Cheol dan Kim, Hyung-Jin. "Sensitivity of earned value schedule forecasting to S-curve patterns". Journal of Construction Engineering and Management, Vol. 140, Issue 7. 2014.

Lipke, W. "Statistical Methods Applied to Project Management”. PMI - Olakhoma City Chapter. 2007.

Lipke, W. "Earned Schedule Schedule performance analysis from EVM measures". Projects and Profits Magazine, India, Vol. XIII, Issue 1. 2011.

Lipke, W. "Schedule is Different".The Measurable News. 2003.

Lipke, W., Zwikael, O., Henderson, K., dan Anbari, F. "Prediction of project outcome: The application of statistical methods to earned value management and earned schedule performance indexes". International Journal of Project Management, Vol. 27, No. 14. 2009

Narbaev, T., De Marco, A. "Combination of Growth Model and Earned Schedule to Forecast Project Cost at Completion”. Journal of Construction Engineering and Management, Vol. 140, No. 1. 2014.

Wicaksono, Y. Seri Solusi Bisnis Berbasis TI: Aplikasi Excel Dalam Menganalisis Data. Alex Media Komputindo: Jakarta, 2006. 

untuk Gedung Bertingkat di Jakarta 